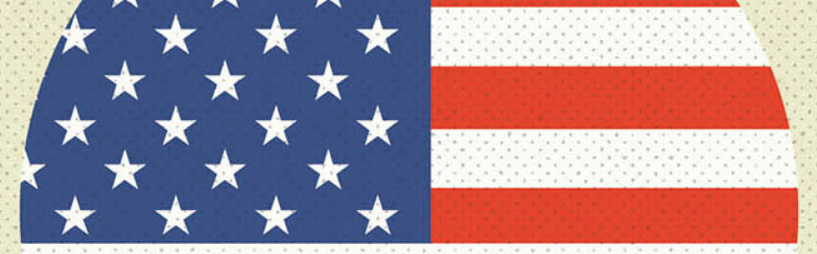




\title{
Estados, governança global e as mudanças na matriz energética mundial: uma análise sob a perspectiva das 'instituições como regimes'
}

\author{
States, global governance and changes in \\ the world energy mix: an analysis from the \\ perspective of 'institutions as regimes'
}

* Francisco Ebeling

\begin{abstract}
Resumo
$\mathrm{O}$ aquecimento global e as suas mazelas implicam na necessidade de alterar radicalmente a matriz energética do mundo. Em um momento de aparente euforia com os investimentos em energia renovável, este artigo tem como objetivo analisar, com base na perspectiva das "instituições como regimes" (Streeck e Thelen, 2009), se o lócus central das mudanças será a dimensão mundial (governança global) ou se os Estados nacionais (governança estatal) carregarão esta responsabilidade. A este nível de governança, é mais fácil taxar o carbono ou subsidiar a transição para fontes de energia renovável. Se ao nível da governança global os 'rule takers' conseguem reescrever as regras a seu favor ou são eles próprios os 'rule makers', ao nível da governança estatal os 'rule makers' conseguem domar, com maior facilidade, os interesses dos 'rule takers'. Neste nível de governança, ainda, a sociedade civil ou a política tradicional - que definimos como 'rule takers' - pode influenciar com maior facilidade essa trajetória, de baixo para cima. Por fim, argumentamos que os interesses econômicos, políticos e geopolíticos dos grandes atores do cenário global - como China e Estados Unidos geram 'externalidades de rede' sobre os regimes de governança global, tornando mais fácil o cumprimento de metas para outros países. No entanto, a mudança será do tipo 'state led', e não 'regime led'.
\end{abstract}

Palavras-chave: instituições como regimes', governança global, governança estatal, mudanças climáticas, matriz energética mundial

\begin{abstract}
Global warming and its effects require a radical change in the world's energy mix. In a moment which seems favorable to invest in renewable energy, this article aims to analyze, from the perspective of "institutions as regimes" (Streeck and Thelen, 2009), if the locus of change will be the global dimension (global governance) or whether states (state governance) will carry this responsibility. At this level of governance, it is easier to tax carbon or subsidize the transition towards renewable energy sources. If at the level of global governance 'rule takers' can rewrite the rules in their favor or are themselves ' rule makers', at the level of state governance the 'rule makers' can tame, with greater ease, the interests of 'rule takers.' In this governance level, still, civil society or traditional politics - which we define as 'rule takers' - can influence more easily this trajectory, from the bottom up. Finally, we argue that the economic, political and geopolitical interests of the major players - for instance China and the United States - function as 'network externalities' for global governance regimes, making the achievement of goals easier for other countries. However, the change will be of 'state led' type, and not 'regime led'.
\end{abstract}

Keywords: 'institutions as regimes', state governance, global governance, climate change, world energy mix

\footnotetext{
* Mestre em Políticas Públicas, Estratégias e Desenvolvimento pelo Instituto de Economia da UFRJ, ebelingbarros@gmail.com
} 


\section{Introdução}

Em setembro de 2013, cientistas do IPCC - Intergovernmental Panel on Climate EChange - lançaram seu quinto relatório sobre Mudanças Climáticas', em que afirmavam que, com 95\% de certeza, a civilização humana seria a principal responsável pelo aquecimento global percebido desde os anos 1950, em função do aumento da emissão dos gases do efeito estufa. De acordo com o relatório, o mundo se aqueceu em média $0,85^{\circ} \mathrm{C}$ entre 1880 e 2012 , sendo que até o final do século XXI esta média alcançaria a marca de $1,5^{\circ} \mathrm{C}$. Tais números afetam, por exemplo, o nível do mar que, entre $1901 \mathrm{e}$ 2010, teria aumentado $19 \mathrm{~cm}$. Até 2100 essa elevação poderia atingir, no pior cenário, $80 \mathrm{~cm}$, sobretudo em função do derretimento das calotas polares. Por fim, os efeitos do aquecimento global impactam também o regime de chuvas, as correntes marinhas e o padrão dos ventos, aumentando a tendência de que ocorram secas e enchentes. As perspectivas são muito negativas por que esses efeitos se reforçam de forma mútua e cumulativa, de maneira que as consequências podem ser ainda mais graves ${ }^{2}$.

A despeito desses números alarmantes e dos graves problemas que podem decorrer deles, as últimas Conferências das Partes (COP) - como as de Copenhagen (2009), Cancún (2010), Durban (2011), Doha (2012), Varsóvia (2013) e Lima (2014) tiveram efeitos práticos limitados ${ }^{3}$. A última, por exemplo, realizada em Lima, tinha como objetivos adotar um texto para a próxima Conferência, a de Paris, além de acordar sob que termos os países irão conceber os seus compromissos nacionais, que possuirão mais um caráter "bottom-up" do que "top-down". Isto é, os países terão relativa autonomia para estabelecer as suas metas e instrumentos. Conforme Jacobs (2014), a despeito das muitas críticas o sucesso do evento reside no fato de que não mais haverá uma cisão entre países em desenvolvimento, como a China, e países desenvolvidos, como os Estados Unidos. A partir de Paris (COP 21), todos os países passariam a carregar uma responsabilidade comum, mas diferenciada de acordo com as respectivas capacidades e circunstâncias nacionais. Dessa forma, as negociações sobre quem reduziria que quantidades de emissões seriam efetivamente realizadas em Paris, mas à luz da percepção de que todos os países do mundo agora são coresponsáveis pelo aquecimento global, ainda que em maior ou menor grau.

Além da aguardada COP 21, em 2015 irá ocorrer, em Addis Abeba (Etiópia) a Third International Conference on Financing for Development. De acordo com Sachs (2014), trata-se de uma oportunidade para reformar o sistema financeiro global, levando em conta a necessidade de conter a "ruína climática". Se até então o sistema financeiro global contribuiu para a difusão em larga escala de fontes fósseis de energia, esta seria uma ótima oportunidade para que esta indústria passasse a canalizar recursos para o desenvolvimento das fontes renováveis de energia, como eólica, solar, geotérmica, bioenergia, etc. A proposta de Sachs (2014), em um momento em que o preço do petróleo está em baixa, é que os governos aproveitem para introduzir impostos sobre o carbono. Ele argumenta que, se cada barril emite 0,3 toneladas de $\mathrm{CO}_{2}$, um imposto 
de US\$ 40 por tonelada custaria apenas US\$ 12 dólares, o que seria razoável para os países que importam petróleo. Assim, de acordo, com Sachs (2014):

"The math is simple. High-income countries emitted around 18 billion tons of CO2 this year - roughly half of all global emissions. If these countries earmarked just \$2 per ton of $\mathrm{CO} 2$ for global financing organizations like the new Green Climate Fund and the regional development banks, they would transfer around $\$ 36$ billion per year. By using part of that money to mobilize private-sector financing, the full $\$ 100$ billion of climate financing could be reached." ${ }^{4}$

No entanto, antes que se realizassem ambas as conferências, os Estados Unidos e a China - os dois países mais poluidores do planeta, com um total de $45 \%$ das emissões - surpreenderam o mundo com um acordo para reduzir as suas emissões de gases-estufa, que não era esperado para antes da Conferência do Clima de Paris (COP21), prevista para 2015, o que abre caminho para mais avanços. Desde já, os EUA comprometem-se a diminuir em $26 \%$ a $28 \%$ a emissão de gases do efeito estufa (como parâmetro, o compromisso da Europa é de reduzi-los em 40\%), e a China a começar a reduzi-la a partir de 2030 .

Neste contexto em que aparentemente há sinais favoráveis no mundo para reduzir as emissões de gases do efeito estufa e, portanto, para amenizar os malefícios do aquecimento global ${ }^{5}$, o objetivo deste artigo é analisar, com base na perspectiva teórica das "instituições como regimes", de Streeck e Thelen (2009), a possibilidade de acelerar as transformações na matriz energética mundial de uma base mais fóssil para uma que seja mais renovável. Nosso objetivo é responder, com base neste modelo teórico, se o lócus central das mudanças será a dimensão mundial (governança global) ou se os Estados nacionais (governança estatal) carregarão esta responsabilidade. A pergunta pode ser entendida também da seguinte forma: o vetor de mudanças é exógeno ou endógeno às economias políticas nacionais? E, finalmente, uma pergunta que diz respeito ao tão alardeado acordo Estados Unidos-China: sua assinatura foi resultado de pressões externas (governança global) ou internas (governança estatal)?

Para responder a estas perguntas, o presente artigo está organizado da seguinte forma. Na primeira seção, examinaremos duas visões (relativamente pessimistas) sobre o futuro da matriz energética mundial: as da Agência Internacional de Energia e da ExxonMobil. Na seção seguinte, apresentamos a perspectiva teórica na qual se embasa este artigo, isto é, as "instituições como regimes" (Streeck e Thelen,2009). Na terceira seção, analisamos a recente trajetória de razoável (in)governabilidade do tema da energia a nível global. Já na quarta seção, vemos como os Estados nacionais têm uma sólida trajetória no apoio do desenvolvimento tecnológico rumo às energias renováveis, que pode ainda ser aprimorada com a possibilidade de que a sociedade civil e a política tradicional participem cada vez mais da co-formatação das políticas públicas que concernem o tema da energia. Por fim, nas conclusões apresentaremos um esboço de resposta sobre o que motivou a assinatura do acordo entre os Estados Unidos e a China, com base no que foi apresentado nas seções anteriores. 


\section{Duas visões sobre o futuro da matriz energética mundial}

O propósito desta seção é apresentar duas visões acerca de como irá evoluir a matriz energética mundial, com um olhar especial para a comparação entre como evoluirão os produtos da indústria de petróleo (petróleo + gás natural) e todas as demais fontes de energia renovável.

O primeiro prognóstico que é analisado é aquele que é feito pela Agência Internacional de Energia (AIE), que publica anualmente seu World Energy Outlook (WEO). Tipicamente, a AIE trabalha com três cenários: o 450, mais otimista em relação à diminuição da demanda por energia, ao aumento da eficiência energética e ao ritmo de maturação das fontes renováveis; o New Policies, intermediário; e o Current Policies, mais reticente quanto à viabilidade dessas transformações. Nota-se que, nos três cenários, apresentados na edição de 2013 do WEO, em 2035 o percentual de petróleo e gás natural se situará em torno dos 50\%, conforme a Tabela 1 apresentada a seguir. Por sua vez, em 2035 o percentual das fontes renováveis poderá alcançar aproximadamente um quarto do total, no cenário otimista. Entretanto, neste artigo nos ateremos ao cenário intermediário (New Policies), de forma que este percentual deverá situar-se na casa dos $17 \%$.

Tabela 1 - As previsões do WEO 2013

\begin{tabular}{|l|r|r|r|r|r|r|r|r|}
\hline & & & \multicolumn{2}{|c|}{$\begin{array}{l}\text { Cenário } \\
\text { New Policies }\end{array}$} & \multicolumn{2}{c|}{$\begin{array}{l}\text { Cenário Current } \\
\text { Policies }\end{array}$} \\
\hline & 2000 & 2011 & 2020 & 2035 & 2020 & 2035 & 2020 & 2035 \\
\hline Carvão & 2357 & 3773 & 4202 & 4428 & 4483 & 5435 & 3715 & 2533 \\
\hline Petróleo & 3664 & 4108 & 4470 & 4661 & 4546 & 5094 & 4264 & 3577 \\
\hline Gás Natural & 2073 & 2787 & 3273 & 4119 & 3335 & 4369 & 3148 & 3357 \\
\hline Nuclear & 676 & 674 & 886 & 1119 & 866 & 1020 & 924 & 1521 \\
\hline Hidroelétrica & 225 & 300 & 392 & 501 & 379 & 471 & 401 & 550 \\
\hline Biomassa & 1016 & 1300 & 1493 & 1847 & 1472 & 1729 & 1522 & 2205 \\
\hline Outras renováveis & 60 & 127 & 309 & 711 & 278 & 528 & 342 & 1164 \\
\hline Total (Mtoe) & 10071 & 13069 & 15025 & 17386 & 15359 & 18646 & 14316 & 14907 \\
\hline $\begin{array}{l}\text { \% Petróleo + Gás } \\
\text { Natural }\end{array}$ & $57,0 \%$ & $52,8 \%$ & $51,5 \%$ & $50,5 \%$ & $51,3 \%$ & $50,8 \%$ & $51,8 \%$ & $46,5 \%$ \\
\hline \% Renováveis & $12,92 \%$ & $13,21 \%$ & $14,60 \%$ & $17,59 \%$ & $13,86 \%$ & $14,63 \%$ & $15,82 \%$ & $26,29 \%$ \\
\hline
\end{tabular}

Fonte: IEA (2013)

Apresenta-se agora a visão da ExxonMobil sobre a evolução da matriz energética mundial, que foi apresentada no "Outlook for Energy - a view for 2040" (ExxonMobil, 2015) - também publicado anualmente.

Na visão da companhia, conforme apresentada por ela no relatório de 2015, em 2040 petróleo e gás natural, isto é, os principais produtos da indústria de petróleo, irão suprir cerca de $58 \%$ da matriz energética mundial, um crescimento de aproximadamente 
2\% em relação a 2010, data mais próxima do presente ano. Este percentual supera em cerca de $8 \%$ a previsão do WEO 2013. No que diz respeito à demanda total por energia, a empresa prevê que esta crescerá 35\% em comparação com 2010, sobretudo em função do maior crescimento dos países em desenvolvimento e do aumento da taxa de urbanização nestes países. Por sua vez, o gás natural cresceria $65 \%$ no período, passando a suprir 25\% das necessidades energéticas em 2040, e assim superando o carvão como principal fonte de eletricidade. A empresa estima ainda que em 2040 a oferta de líquidos chegará a 110 milhões de boe/d (barris de óleo equivalente por dia), ante aproximadamente 90 milhões em 2010. Boa parte dessa oferta incremental viria de óleos não convencionais, como o das águas ultra-profundas brasileiras. Na outra direção, as energias renováveis (biomassa, hidrelétrica e outras renováveis) cresceriam apenas $1,8 \%$ no período indicado, passando a representar cerca de $15 \%$ da matriz energética mundial, atingindo uma previsão similar ao do WEO 2013, que é de 17\%.

No que se segue, apresentamos a evolução da matriz energética de alguns países selecionados. Vemos que, em todos estes casos, há sinais contraditórios quanto à implantação ou não de mais fontes de energia renovável. No médio prazo, pelo menos, não há o menor indício de que as fontes fósseis serão descontinuadas abruptamente.

\section{O Brasil}

A grande novidade do WEO 2013 foi a publicação de um estudo especial sobre o passado, o presente e o futuro da energia no Brasil. Neste cenário, há previsões bastante otimistas sobretudo no que concerne a produção de petróleo - em função da exploração do pré-sal, o Brasil tornar-se-ia uma das principais fronteiras de expansão da produção de petróleo no mundo nas próximas décadas. Segundo a publicação, o Brasil produziria algo em torno de 6 milhões de barris em 2035 - com investimentos médios em E\&P que alcançariam uma média anual de US\$ 60 bi até 2035, em uma previsão evidentemente exagerada dados os parâmetros atuais ${ }^{6}$.

Não obstante, isso não significa que o Brasil não invista também em fontes alternativas de energia. Atualmente está em construção, a ritmo acelerado, a Usina de Belo Monte, que adicionará 11GW ao parque gerador brasileiro, que atualmente conta com uma capacidade instalada de 133GW. Ademais, entre 2002 e 2013, o país logrou aumentar mais de cem vezes o seu consumo de energia eólica, de 0,1 para 6,5 Terawatts-hora, reduzindo ainda dramaticamente o seu custo unitário de geração. Também estão sendo feitos investimentos em etanol, biodiesel e em bioeletricidade. O WEO 2013 prevê que em 2035 o país logrará produzir cerca de 800.000 boe/d, principalmente em função da maciça expansão do chamado "etanol de segunda geração". Na direção contrária, o estímulo à produção de etanol foi desencorajado com a extinção da CIDE e os investimentos em energia solar ainda são tímidos, muito embora tenha sido realizado um leilão para que esta fonte de energia passasse a ter um papel na matriz energética do país. 


\section{A Bolívia}

De acordo com Svampa (2013), estaria atualmente em curso uma transição do consenso de Washington para o "consenso das commodities", em que países exportadores de commodities enxergariam na implementação de projetos de larga escala de extração de minérios, energéticos ou alimentos um imprescindível driver para o seu crescimento. Inspirados por ideias desenvolvimentistas, governos progressistas vislumbrariam a possibilidade de escapar da "maldição dos recursos naturais" ao reinvestir as divisas obtidas com a venda desses produtos em setores da economia com maior valor agregado, principalmente em tempos de elevados preços das commodities. Em particular, a Bolívia aposta na extração e na exportação de seu gás natural aos vizinhos Brasil e Argentina como forma de propulsionar seu crescimento econômico e social.

\section{A Alemanha}

Através de um variegado programa de incentivos públicos (Mazzucato, 2013), a Alemanha tornou-se, nas últimas décadas, umas das principais potências em termos de geração eólica do mundo. Contudo, nos próximos anos o país diminuirá esses incentivos, de forma que os geradores alemães terão que competir com as plantas instaladas em outros países da União Europeia, muitas delas movidas a gás natural ou a carvão. No que diz respeito ao biodiesel, o país praticamente descontinuou o seu programa de expansão ${ }^{7}$, o que resultou na quebra de uma grande quantidade de produtores, reduzindo também os incentivo à P,D\&l no campo a um mínimo. Em face do medo de perder a competitividade frente aos países asiáticos e aos Estados Unidos, a indústria pressiona para que o país desacelere a assim chamada "Energiewende", o que implicaria recorrer mais ao gás natural russo (ou ao shale gas, um potencial ainda não muito explorado) para fins de geração elétrica.

\section{Os Emirados Árabes Unidos}

Os Emirados Árabes Unidos tem realizado maciços investimentos em energia renovável, contando atualmente com um portfólio de 2,500 Megawatts de capacidade instalada. Ademais, foram feitos investimentos na mitigação das emissões do carbono e em eficiência energética. Na direção contrária, o país pretende expandir, até 2020, sua capacidade instalada de produção de petróleo, de 2,9 para 3,5 milhões de barris/ dia. Suas duas companhias aéreas estatais (Emirates e Etihad) - que nos últimos anos expandiram rapidamente sua clientela e tornaram-se referência em qualidade no setor baseiam sua vantagem competitiva na disponibilidade de querosene de aviação (QAV) barata. Finalmente, Dubai, este hub de negócios e de consumo conspícuo, deve seu vertiginoso crescimento à abundância dos dólares arrecadados pelo emirado vizinho - Abu Dhabi - com a venda de petróleo e gás natural. 


\section{Os Estados Unidos}

Os Estados Unidos sempre foram, historicamente, o maior importador de petróleo do mundo. Entretanto, nos últimos anos a política energética do país e maciços investimentos privados têm sido canalizados para alterar este quadro. Em 2013, se $51,17 \%$ da nova capacidade instalada de geração elétrica veio do gás natural, as energias renováveis responderam por 37,16\% da energia adicional (5,279 MW). $O$ destaque ficou para a energia solar, que responde por $21 \%$ do total (2,936 MW). De acordo com recente relatório da IRENA ${ }^{8}$, os Estados Unidos poderiam chegar a 2030 com $50 \%$ da sua energia elétrica sendo gerada por painéis solares. Além da maior segurança energética, esses investimentos têm o propósito de ajudar a recuperação da combalida economia norte-americana. Um exemplo é a criação de empregos: de acordo com a Solar Foundation', em 2014 foram gerados 174 mil empregos no setor, mais do que pela indústria petrolífera. No entanto, na outra direção, de acordo com o BP Energy Outlook 2030, em 2030 os Estados Unidos produzirão 16 milhões de barris diários de petróleo, ante uma produção atual de cerca de 10 milhões. Esse incremento virá, sobretudo, das fontes não-convencionais, como as areias betuminosas e o tight oil. A essa produção se adiciona o controverso potencial do shale gas. Além disso, suas empresas petrolíferas - como ExxonMobil e Chevron - continuam explorando petróleo e vendendo derivados em todas as partes do mundo e ainda pertencem ao seleto grupo das empresas mais ricas do planeta.

\section{A China}

A China, cujas grandes cidades são conhecidas mundialmente por, dentre outras coisas, serem extremamente poluídas - em função da rápida expansão industrial ocorrida nas últimas décadas, movida à queima do carvão mineral - recentemente passou a apostar em uma mudança radical de trajetória. De acordo com Jiankun e Stern (2014), o país tornou-se o maior investidor em energias renováveis do planeta, com um recorde de US\$ 68 bilhões destinados para este fim em 2012. Em 2013, essa soma alcançou US\$ 54 bilhões. Ademais, sua oferta de energia não fóssil dobrou de 2005 a 2013, enquanto a sua intensidade do $\mathrm{CO}^{2}$ por unidade de PIB produzida caiu em $28 \%$. Na contramão disso, para atender a uma demanda cada vez maior de veículos automotivos, as quatro petroleiras chinesas - Petrochina, CNOOC, CNPC e SINOPEC, aumentam drasticamente os seus investimentos e a sua produção de petróleo. Em 2013, a Petrochina foi a empresa que mais investiu em E\&P no mundo; ao passo que no mesmo ano a China alcançou uma produção de 4,2 milhões de barris por dia, que lhe dá a quarta posição no ranking mundial de produtores, atrás apenas da Arábia Saudita, da Rússia e dos Estados Unidos. No Brasil, a CNOOC (10\%) e a CNPC (10\%) participaram do lance vencedor que adquiriu o bloco de Libra, o primeiro sob o regime de partilha. Por seu turno, a Sinopec adquiriu as operações da Repsol no país (RepsolSinopec). 


\section{A perspectiva das instituições como regimes}

Para entender a forma como se processam as mudanças institucionais em uma dada economia política, Streeck e Thelen (2009) concebem as instituições como regimes. Um regime é definido como:

"a set of rules stipulating expected behavior and 'ruling out' behavior deemed to be undesirable. (.....) Regimes involve rule-makers and rule-takers, the former setting and modifying, often in conflict and competitition, the rules with which the latter are expected to comply. (Streeck e Thelen, 2009, p. 108)"

Neste diapasão, os atores sociais (rule takers) buscariam a todo tempo reinterpretar as regras societais a seu favor, de tal maneira que nem sempre o que é pretendido pelo formulador das regras (rule-makers) é alcançado. Os autores enfatizam que, como há limites à capacidade de antever todas as possíveis reações dos rule takers e de antecipar a consequência desses atos, os rule makers deliberadamente mantém algum grau de não especificação nas regras (ibidem, p. 110-2). De uma forma geral, para Streeck e Thelen (2009) a mudança institucional pode ser descrita como um processo dinâmico, contínuo, e muitas vezes silencioso. Ao longo deste artigo, utilizaremos as "instituições como regimes" tanto no contexto da "governança global do clima", como para definir a “governança estatal", na acepção de Diniz (1995, 1996, 1998a, 1998b) ${ }^{10}$.

\section{A ingovernabilidade do tema da energia a nível mundial}

Em 2009 o Brasil participou da Conferência das Partes (COP15) sobre as Mudanças Climáticas de 2009, que culminou no Acordo de Copenhagen. Neste, não se concretizou a assinatura de novo acordo vinculante para todos os signatários. Entretanto, ratificouse o compromisso de procurar limitar o aumento de temperatura em $2,0^{\circ} \mathrm{C}$ e de que os países apresentassem a cada dois anos relatórios nacionais das suas emissões. Além disso, seus signatários foram convocados a confirmarem propostas de compromissos anunciadas durante a conferência.

Neste contexto, o Brasil apresentou como contribuição voluntária metas nacionais que representariam uma redução entre 36,1\% e 38,9\% das emissões projetadas até 2020. Estas foram estabelecidas pela Política Nacional sobre Mudança do Clima PNMC, de 2009, ratificadas em lei ${ }^{11}$. A referida política, além de estipular as metas, apresentou os instrumentos ${ }^{12}$ que passariam a ser utilizados para alcançá-las, bem como os setores em que se pretendia evitar mais emissões. A estratégia brasileira concentrou-se na redução do desmatamento da Amazônia e no Cerrado ${ }^{13}$, que será responsável por mais de $60 \%$ das reduções das emissões, isto é, $24,7 \%$ em relação aos $36,1 \%$ ou $38,90 \%$ do total pretendido. Já no setor energético, se pretende reduzir $19,79 \%$ do total, o que representa, respectivamente, $6,1 \%$ e $7,7 \%$ no total absoluto.

Grosso modo, a Política Nacional sobre Mudança do Clima - PNMC optou por sacrificar menos aquela atividade que é central ao projeto de desenvolvimento 
brasileiro nas próximas décadas. O setor petrolífero, a cadeia automobilística e o setor de aviação são centrais em um eixo infraestrutural-energético a partir do qual se pretende continuar gerando empregos e criar efeitos desencadeadores nas respectivas cadeias.

A partir dessa escolha, considerando que o percentual de redução das emissões é calculado em cima das emissões previstas para ocorrerem em 2020, o balanço tenderá a ficar muito menos favorável para o setor energético. As pesadas ações de mitigação previstas no plano reduzirão para cerca de $40 \%$ as emissões decorrentes do desmatamento, ao passo que a menor ênfase no setor de energia irá torná-lo responsável por um terço das emissões em 2020 - ante a aproximadamente $16 \%$ em 2005 -, segundo Serôa da Mota (2011).

Não obstante, a indústria de petróleo ainda se gaba de que sua responsabilidade

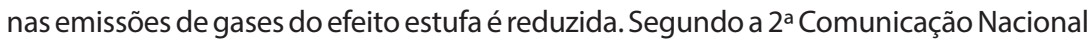
do Brasil à COP15, o setor de energia brasileiro propriamente dito foi responsável por $3,0 \%$ das emissões totais de $\mathrm{CH} 4$ (gás metano), sendo 1,9\% associado à queima de combustíveis fósseis e $0,8 \%$ à extração ${ }^{14}$, transporte e processamento de petróleo e gás natural. A exploração do pré-sal tende a aumentar este último percentual por que há um grande desafio logístico e tecnológico associado ao escoamento e ao aproveitamento por parte do mercado nacional do percentual de gás natural que não é permitido queimar ${ }^{15}$. Ademais, uma vez resolvidos esses desafios logísticos, de qualquer maneira estimula-se a queima de $\mathrm{CO}_{2}$ por parte dos consumidores finais.

Contudo, é preciso ressaltar que nem todos os gases poluentes ${ }^{16}$ que correspondem ao petróleo e ao gás natural produzido ou queimado no pré-sal serão emitidos no país, em função das exportações projetadas. De acordo com Bridge e Le Billon (2013), em 2009 o petróleo foi responsável por 20\% das emissões antropogênicas de $\mathrm{CO}_{2}$. Este é um percentual que tende a aumentar se os preços do petróleo permitirem a exploração das fontes não-convencionais, onde há uma necessidade adicional de energia para converter óleos pesados e sulfurosos em combustíveis destinados para o transporte. Ainda de acordo com os autores, cerca de $80 \%$ das emissões do ciclo dos combustíveis advém da combustão final (IBID). Embora estas possam ser reduzidas através de tecnologias mais limpas e eficientes, o $\mathrm{CO}^{2}$ não deixará de ser emitido. Ademais, as tecnologias que permitiriam reduzir as emissões de carbono dos veículos por completo ainda estão em um estágio bastante inicial de desenvolvimento.

Assim, nem o maior dos esforços nacionais para tornar a cadeia de petróleo e gás e de transportes rodoviários ambientalmente mais sustentável será suficiente se não for acompanhado de esforço similar nos demais países. Reduzir as emissões de gases poluentes pela combustão de derivados de petróleo e gás e ao mesmo tempo substituir essas fontes por energia renovável requer um esforço a nível global. Mas esta é uma tarefa de difícil consecução, por que, como argumentam Bridge e Le Billon, "the contemporaneous oil governance - the set of rules and organizations that guide how decisions over oil are made - is fragmented and incoherent, consisting mostly of 
a patchwork of organizations with mandates focusing on the vested interests of their members" (Bridge and Le Billon, 2013, p. 155).

$\mathrm{O}$ que isso significa? Se, de um lado, a comunidade petrolífera internacional tem logrado razoável sucesso na adoção de convenções marítimas que dispõe sobre a forma como o petróleo é produzido e transportado ${ }^{17}$; de outro, pouco se avançou na estipulação de limites da queima desses gases ou em direção ao fomento de fontes alternativas de energia de forma verdadeiramente consequente. Como vimos na primeira seção deste artigo, em 2035 apenas 17\% da energia consumida no mundo advirá de fontes renováveis. Na nossa visão, há dois principais fatores que explicam essa dificuldade a nível global. De um lado, as instituições globais que regem os mercados de petróleo; de outro, o mecanismo de funcionamento das United Nations Climate Change Conferences, conhecidas como COPs.

\section{O papel das organizações, das empresas e dos mercados de petróleo}

Organizações internacionais como a Agência Internacional de Energia (AIE) ou empresas como a ExxonMobil possuem o que Dugger e Sherman (2000) chamam de "interesses investidos". A primeira representa os interesses dos países da OCDE, isto é, sobretudo dos importadores de petróleo e gás natural, que gostariam de dispor de energia razoavelmente barata e abdicariam, com gosto, do risco geopolítico do fornecimento dessa energia, seja esta fóssil ou não. Por sua vez, a ExxonMobil é reconhecidamente uma empresa que aposta em um futuro fóssil, como mostra Coll (2012). Portanto, suas análises possuem algum grau de conteúdo ideológico. Para tal, parece-nos oportuna a seguinte citação de Terry Eagleton:

\footnotetext{
"Mas se a ideologia, neste sentido, é discurso primariamente performativo, retórico, pseudoproposicional, isso não significa que seja desprovida de um importante conteúdo proposicional, - ou que as proposições que faz inclusive as morais e normativas, não possam ser avaliadas quanto a sua verdade ou falsidade. Muito do que as ideologias dizem é verdadeiro e seria ineficaz se não o fosse, mas as ideologias também têm muitas proposições que são evidentemente falsas, e isso não tanto por causa de alguma qualidade inerentemente falsa, mas por causa das distorções a que são submetidas nas suas tentativas de ratificar e legitimar sistemas políticos injustos opressivos. (Eagleton, 1997, p. 193)"
}

Da prévia citação, extraem-se, para o nossos propósitos, as seguintes observações: a análise da AIE sobre como evoluirá a matriz energética mundial é uma proposição normativa a determinados atores da rede mundial de produtores de energia de como tomar as suas decisões de investimento, calcada nos valores e prioridades da OCDE. Contudo, esta proposição possui algum "grão de verdade". Podemos, dessa maneira, aceitar, com algum grau de confiança, que o futuro da matriz energética mundial se assimilará bastante ao que prevê a AIE. Isso por que, como mostram McNeish e Logan (2012), a dependência global do petróleo pode ser aceita com relativa facilidade 
como um fato comprovado, em função da escolha pretérita de um modelo de desenvolvimento centrado no automóvel, que se convencionou chamar de "urban sprawl ${ }^{\prime \prime 18}$, um fenômeno típico dos Estados Unidos, mas que se disseminou em outros países, como a China e o Brasil. Em resumo, a AlE buscaria, de forma muito sutil, influenciar a oferta futura de energia no mundo, podendo esta ser de origem fóssil ou não. O otimismo da Agência com as perspectivas brasileiras de se tornar um grande exportador de petróleo e um grande produtor de etanol de segunda geração pode ser entendida nesta "clave explicativa".

Por sua vez, a ExxonMobil procura influenciar mais ativamente o mercado internacional de petróleo rumo a um futuro fóssil. De acordo com Zalik (2010):

"at the global scale a set of possible futures laid out by the oil industry are heavily influenced by the embeddedness of petroleum corporations (and capitalist agents within those corporations) in the trading dynamics on future markets. Here social relations among business agents shape perceptions of supply and demand." (Zalik, 2010, p.563)

Neste diapasão, interpreta-se que, em grande parte, a estratégia da ExxonMobil - uma empresa cuja reputação é de solidez e de ter bons princípios administrativos (Coll, 2012) -, com a publicação de seu "Outlook for Energy - a view for 2040", é a de influenciar outros atores do mercado de petróleo de que o futuro da energia no mundo será ainda bastante dominado pelas energias fósseis, ainda que crescentemente pelo gás natural, que também faz parte de seu core business. Embasa essa visão o cálculo de que provavelmente os governos não tomarão as medidas necessárias para limitar o aquecimento global, uma vez que outras preocupações, como o terrorismo ou o crescimento econômico, sobrepor-se-iam, nas agendas governamentais, às preocupações com a destruição ambiental.

Neste contexto, a indústria "venderia" a ideia de que os esforços atualmente empreendidos para encadear uma transição energética já seriam os máximos possíveis e de que a transição para uma matriz energética mais limpa só será possível quando as fontes alternativas de energia forem economicamente viáveis. Essa é a razão pela qual algumas petrolíferas, como a Shell e a BP, investem um percentual (limitado) dos seus orçamentos em P,D\&l em pesquisa científica e "abracem a tecnologia como a solução para os males do mundo" (Gustafson, 2012, p. 315) ${ }^{19}$.

Na realidade, o lobby da indústria é antigo, e remonta à época quando a pauta ambiental passou a existir. As empresas petrolíferas, desde cedo, trataram de minimizar os riscos ambientais decorrentes da queima de gases do efeito estufa, argumentando, por exemplo, que a energia nuclear traria problemas ainda maiores (Mitchell, 2011). Desde muito cedo, como mostra Mitchell (2011), uma fração de algumas fortunas familiares originárias do negócio petrolífero teria sido revertida para think tanks neoliberais que, por sua vez, apoiaram ativamente o "conjunto de ferramentas" adotado para solucionar os problemas do clima, sobretudo aqueles ratificados pelo Protocolo de Kyoto. Este lobby resultou ainda que a indústria passasse a receber 
generosos subsídios e vantagens fiscais, de acordo com Magdoff e Foster (2011). Finalmente, como mostra Bond (2012), o lobby da indústria teve um efeito sobre a elite política mundial, que adiaria o momento em que efetivamente lidaria com a questão climática. O Brasil, por exemplo, que se anima com a possibilidade de vender petróleo como exportador e de reverter seu lento processo de desindustrialização, é um dos atores da elite política mundial que pode ser facilmente seduzido pelo lobby e pelo discurso das empresas privadas, como discute Bond (2012).

O país é um participante do que Nayyar (2013) chama de"a corrida pelo crescimento". Países asiáticos que até 40 anos atrás tinham o mesmo padrão de desenvolvimento do Brasil - ou até mesmo inferior - atualmente tornaram-se potências manufatureiras e, sobretudo, tecnológicas, ameaçando inclusive o domínio europeu e norte-americano neste último campo. Por sua vez, os países da semi-periferia vislumbram a possibilidade de alcançar os países desenvolvidos através de políticas desenvolvimentistas. A corrida pelo crescimento é, portanto, simultaneamente, uma corrida por matérias primas e um imperativo pela busca por segurança energética. Ademais, como mostra David Harvey, há um imperativo que impele à infindável acumulação de capital a taxas compostas (Harvey, 2010), tanto nos países desenvolvidos como naqueles que participam da "corrida pelo crescimento". Na sua argumentação, capitais que não atendem a este chamado são eliminados do jogo - sejam estes petrolíferas, fundos especulativos ou bancos. Os elevados preços das commodities - não só do petróleo - são oportunidades que não podem ser perdidas por esses atores, e que se refletem também nas decisões de investimentos das petrolíferas. Mas como chegamos a este ponto?

O preço do petróleo assim como o conhecemos afirmou-se como um produto financeiro nos anos 1980. No início daquela década, nas franjas do petróleo vendido pela OPEP, lentamente surgiram mercados spot, que ainda eram físicos. Dentre estes, consolidou-se o WTI, negociado pela NYMEX, que atualmente regula as transações realizadas no mercado americano e nas Américas. Mais adiante, surgiu o Brent, comercializado em Londres, que atualmente rege as transações realizadas na Europa. O Brent tornou-se uma referência para o mercado de petróleo como um todo quando a OPEC, sob a liderança da Arábia Saudita, desistiu de regular, simultaneamente, quantidades e preços. Como mostra Yergin (2003), os preços vendidos nesses mercados são voláteis, o que requereu a criação de mecanismos que minimizassem os riscos. Criaram-se os mercados futuros, onde os participantes do mercado adquirem o direito à uma commodity em algum momento do futuro (Yergin, 2003). Essa prática é conhecida como hedging (Carollo, 2012; Pinto Jr., 2007). Ao longo dos anos 1990, no auge das ideias liberais, cresceu a participação de bancos e demais investidores nestes mercados. Havia a percepção de que quanto mais participantes fossem ativos neste mercado, mais eficiente este se tornaria - em outras palavras, maiores seriam as chances de que os preços do petróleo refletissem fidedignamente oferta e demanda futura por petróleo e derivados de petróleo. Tudo ia bem até 2008, quando a crise mundial fez com que os preços despencassem abruptamente. Argumentou-se que nos 
anos 1990 eles estavam baixos em função dos escassos investimentos realizados na década anterior e que nos 2000 o aumento dos preços era explicado pelo aumento da demanda asiática por petróleo, em especial a chinesa. Com a queda abrupta do preço, que na realidade não refletia fidedignamente o balanço entre a oferta e a demanda por petróleo e derivados, ganhou força o argumento de que o que alimentava a alta dos preços era a especulação, e não simplesmente a percepção dos atores acerca do futuro e da oferta e demanda por petróleo (Serrano, 2008).

Mais recentemente, a queda abrupta do preço do petróleo, deliberadamente provocada pela Arábia Saudita, pôs também em xeque as visões tradicionais acerca do funcionamento do mercado do petróleo ${ }^{20}$. Se existe um equilíbrio entre e oferta e demanda neste mercado, este é garantido pela atuação da Arábia Saudita como swing producer. Em outras palavras, aquele país coloca no mercado o excesso de oferta (ou dele retira a falta de oferta) de forma a manter o preço do petróleo numa faixa que remunere adequadamente a todos os atores envolvidos, considerando que os custos de produção em áreas como o pré-sal ou nas areias betuminosas podem ser muito elevados. A tendência é, então, que países como Estados Unidos ou Rússia diminuam sua produção para que os preços voltem a um patamar viável para todos os participantes do mercado mundial de petróleo.

Em resumo, a forma como os mercados internacionais de petróleo são organizados estimula que os países continuem produzindo petróleo e gás. Se há um movimento para introduzir um imposto sobre o carbono quando o preço do petróleo está baixo, como sugere Sachs (2014), altos preços podem igualmente desencorajar essas iniciativas.

\section{A governança neoliberal do clima}

As chamadas Conferências das Partes (COPs) - que também influenciam o quanto de energia limpa será produzida - ganharam em proeminência com a assinatura do Protocolo de Kyoto, que foi concebido em um momento em que as ideias econômicas ortodoxas eram hegemônicas (Nobre e Amazoas, 2002). Este concebeu instrumentos que permitiram que as reduções das emissões fossem realizadas em outros países, inclusive naqueles sem metas, por meio de mercados de direitos e/ou créditos de emissão. Segundo Serôa da Motta (2011), essa flexibilidade aumentaria a chance de que as metas fossem cumpridas, minimizando ainda custos e estimulando o desenvolvimento sustentável em países em desenvolvimento. Surgem neste âmbito os assim chamados Mecanismos de Desenvolvimento Limpo - MDLs, que financiariam projetos de reduções de emissões nos países em desenvolvimento.

Mas, por uma série de razões, a solução pelos mercados mostrou-se incompleta ou incapaz de solucionar heroicamente o problema que se propôs a resolver. Uma possível interpretação é que o acordo, na realidade, nasceu "natimorto". Serôa da Motta (2011) argumenta que, embora o Protocolo de Kyoto tenha sido um marco 
inicial de cooperação global em relação à busca pela redução da emissão dos gases na atmosfera, (i) os principais emissores, como os EUA, não ratificaram o acordo, (ii) as suas metas foram insuficientes; e (iii) não previram que sem a colaboração dos emergentes China, Índia e Brasil. Em análise escrita mais de uma década depois, Newell e Paterson (2010) mostram que (i) alguns países como China, Índia e Brasil recebem muitos MDLs (60\% os três somados), enquanto outros não são alvos desses projetos e (ii) no âmbito do MDL as transações se dão entre países, de forma que os mercados não são completos e não há um número suficiente de compradores e vendedores. Por sua vez, como argumenta Stilwell (2012), um "Emission Trading Scheme (ETS)" efetivamente confere o direito de poluir, pois seu comprador terá adquirido este direito. Gerase então um incentivo econômico a prosseguir com a atividade ambientalmente degradante, geralmente em países do terceiro mundo.

Diante desses fracassos, outras soluções foram propostas mais à frente, por exemplo na Rio+20, que foi convocada com a "intenção de consolidar e operacionalizar o novo paradigma da sustentabilidade, através da economia verde e da erradicação da pobreza" (Camargo, 2012, p. 21). O conceito de economia verde, antes "privativo até então de um grupo especializado em economia ecológica (ibidem)" começou a ganhar corpo no âmbito da crise de 2008. À época, especulava-se a criação de um "global new deal" de cunho ambiental, que reativasse a economia e criasse empregos, ao mesmo em que levasse em consideração o aquecimento global, a degradação ambiental e a pobreza. Assim, em 2008 o PNUMA lançou seu "Green Economy Initiative" e o "Global Green New Deal" (GGND). No início de 2011, o organismo da ONU publicou outro estudo, intitulado "Rumo à Economia Verde: Caminhos para o Desenvolvimento Sustentável e a Erradicação da Pobreza". O novo estudo estimou os valores de investimentos para viabilizar a economia verde em 1,3 trilhões de dólares, cerca de $2 \%$ do PIB global. Outro tema central da conferência Rio+20, como mostra Camargo (2012), foi a governança global, após o diagnóstico de que na realidade o PNUMA é apenas um programa com ações limitadas, incapaz de viabilizar financeiramente a promoção, a nível global, de uma "economia verde". Por ter surgido em tempos de crise econômica, o ímpeto de que é possível criar uma "economia verde" a nível global, de cima para baixo, esvaziou-se diante de perspectiva de que a já grave crise financeira internacional se agravasse ainda mais, o que resultaria na reversão de prioridades.

A nossa interpretação é a de que para compreender adequadamente o porquê dos investimentos em energias renováveis continuarem limitados em detrimento das fontes fósseis, é necessário recorrer à Gill (2012) e a seu "novo constitucionalismo". A contribuição de Gill (2012) para a teoria da governança parte da constatação de que a retórica neoliberal requer que o Estado estabeleça fundações legais e institucionais para uma governança orientada para o mercado e uma reestruturação social que garanta proteção ao capital, o que ele chama de "novo constitucionalismo" (cf. Short, 2012). Em oposição ao constitucionalismo tradicional, onde os direitos dos indivíduos são respeitados, o novo constitucionalismo "confere direitos privilegiados de cidadania ao 
capital corporativo" (Gill, 2012, p. 132, tradução livre) ao impor disciplina às instituições públicas e ao isolar aspectos centrais da economia do controle democrático, como, por exemplo, as políticas macroeconômicas. Isso é alcançado através da assim-chamada 'multi-level governance', que é a redistribuição de autoridade política entre níveis jurisdicionais, de forma que as 'market-inhibiting policy competencies' sejam entregues a níveis do governo que não constranjam o capital e o seu livre fluxo.

O "novo constitucionalismo" e a "multi-level governance" - garantidos de cima para baixo - foram cruciais para que se consolidasse nas últimas décadas o que Di Muzio (2012, p. 83), chama de "governamentalidade neoliberal". Para o autor, a "governamentabilidade neoliberal" - que regeria a governança petrolífera e a do clima - não estaria preparada para mitigar os efeitos perversos da civilização "petromercado" por empregar táticas e técnicas inapropriadas, como mercantilização, privatização, desregulação, responsabilização individual e a criação de incentivos às firmas. A alocação de recursos através dos mercados levaria a resultados indesejáveis e inapropriados desde o ponto de vista climático, como a exploração das areias betuminosas no Canadá e de fontes não-convencionais no Ártico, tal como mostra Shah (2004).

\section{Rule makers vs. Rule takers ou Rule makers como Rule Takers?}

Do ponto de vista da teoria que expusemos ao longo deste artigo, se há uma "instituição como regime" que estipula limites à queima desses gases ou que fomente fontes alternativas de energia a nível global, nesta os "rule takers" têm larga vantagem sobre os "rule makers". Na realidade, em grande parte os "rule takers" são os próprios "rule makers", já que são as grandes potências - sobretudo, Estados Unidos, China e Rússia - que tornam praticamente inviável a estipulação de regras verdadeiramente consequentes a nível global. Em outra clave, seguindo Brunnenheimer (2008), talvez seja possível afirmar que, a este nível de governança, os atores estratégicos que exercem liderança ao lado do "input" - que compreende desde a extração até a queima do petróleo - confundem-se com aqueles que a exercem ao lado do "output", que diz respeito aos debates e negociações sobre como os gases do efeito estufa produzidos do lado do "input" são neutralizados. Assim, no atual estágio, como veremos na próxima seção, cabe a cada governança estatal, de acordo com os seus meios e idiossincrasias domésticas, estipular a própria estratégia de diminuição das emissões dos gases do efeito estufa ou de estímulo às renováveis.

\section{Por que e como os Estados?}

Nesta seção, o objetivo é demonstrar o papel de liderança que os Estados nacionais terão na transição para matrizes energéticas mais limpas, muito embora, em alguns casos, a transição irá requerer a cooperação inter-estatal e outros tipos de integração 
regional. É ao nível dos Estados nacionais que os"rule makers" ainda conseguem domar, ou ao menos controlar, a agência dos "rule takers". É ao nível dos Estados nacionais que a governança estatal pode ter alguma efetividade por que, como mostra Weiss (1998), a globalização não implica em uma uniformização das práticas estatais de acordo com os desígnios neoliberais. Ao contrário, para Lister e Marsh (2005), a aceitação ou não de práticas ou instituições impostas pelo senso comum global é mediada por um "filtro ideacional doméstico". Por fim, Diniz acredita que mesmo no âmbito da globalização econômica e política os Estados possuem margem de manobra para exercer um papel mais ativo ou inverter posições de desvantagens (Diniz, 2007).

\section{Os impostos sobre o carbono}

Uma sugestão muito difundida na comunidade epistêmica internacional é a de que se deve adotar, do lado da oferta, um imposto sobre o carbono, idealmente a nível mundial, que desencoraje a demanda e a produção de petróleo e gás, em prol das energias renováveis. Tal visão, no atual contexto, é evidentemente de difícil implementação. A nível nacional, no entanto, tais impostos já existem em alguns países como o Chile, a Noruega e a Suécia. Outro exemplo de imposto é a atualmente desativada CIDE, cujo propósito inicial era incentivar as energias renováveis (Silva, 2007). Na nossa visão, impostos sobre o carbono podem ter um impacto sobre a adoção de energias renováveis, principalmente quando estes abastecem o lado da demanda. Em outras palavras, se o imposto sobre o carbono for direcionado para um fundo que, de forma transparente, estimule a adoção dessas fontes, há chances de sucesso. De fato, como mostra Fiori (2014), a cobrança de tributos tem uma ligação direta com a gênese dos Estados nacionais modernos. A partir dessa gênese, que, de acordo com o autor, remonta no mínimo ao período compreendido entre os anos 1150 e 1350-1400, os Estados nacionais se consolidaram cada vez mais enquanto "Estados impositivos" (Musgrave, 1980-1981). Por sua vez, seguindo a análise de Joseph Alois Schumpeter acerca do "tax state", Offe (2006) argumenta que os Estados são estruturalmente dependentes da tributação, que advém do processo de acumulação capitalista. Nesse contexto, são os Estados, e não as instituições globais, que se consolidaram como entes tributadores por excelência.

\section{Subsídios e o 'big push'}

Van der Ploeg (2011) argumenta que a solução do imposto sobre o carbono é difícil de consecução e propõe que se subsidie a produção de energias renováveis. Baseando-se na regra de Hotelling, o autor argumenta que, subsidiando as fontes de energia renovável seria possível que estas tivessem a mesma taxa de retorno (ou maior) que as fontes fósseis, de forma que os produtores de energia fóssil preferissem produzir a energia limpa. O problema do modelo proposto por Van der Ploeg - e esta é uma crítica que se pode imputar ao mainstream da economia ecológica de uma 
forma geral - é que este se baseia no estabelecimento de alguma taxa de retorno de longo prazo. Mas, como mostra Winnett (2012), numa perspectiva pós-keynesiana, no longo prazo há extrema dificuldade em estabelecer uma taxa de retorno "eficiente". A despeito dessa pequena dificuldade, a solução proposta por Van der Ploeg tem a sua relevância, pois aponta na direção correta.

Em clave similar à de Van der Ploeg, mas metodologicamente distinta, Mazzucato (2013) advoga por uma mistura entre as ideias de Keynes e Schumpeter. Do primeiro, ela toma a necessidade de que o Estado faça uso de políticas fiscais e monetárias expansionistas. Do segundo, de que invista mais focadamente em atividades que criem um impacto maior, sobretudo em P,D\&l. A autora enfatiza, ainda, a importância dos "sistemas de inovação" que, quando existem, diminuem a necessidade do Estado gastar mais em termos absolutos, uma vez que, em função da estrutura oferecida por estes sistemas, os gastos tornam-se mais eficientes. Por sua vez, com base nas ideias do livro de Carlota Perez (2003), Drechsler (2011) mostra que na fase inicial do desenvolvimento de novas tecnologias, tais como as energias renováveis ou os carros elétricos, a atuação do Estado é indispensável. Este pode ter que incorrer em custos afundados sem os quais um push off daquela nova trajetória tecnológica - ambientalmente mais correta - provavelmente não seria possível, já que poucos investidores privados - venture capital ou private entrepreneurs - têm a disposição de assumir o risco. Por fim, em artigo recente Rodrik (2015) defende a criação de "public venture capitals", onde o Estado seria o proprietário da tecnologia renovável a ser desenvolvida. Em resumo, o Estado é, no processo de difusão de tecnológica, o principal ente que subsidia e/ou facilita a difusão das fontes de energias renováveis, permitindo que alguns capitais, em linha com Harvey (2010) se acumulem infindavelmente a taxas compostas dentro dos parâmetros de uma "economia verde energética". Mesmo que a cultura empresarial de algumas empresas tenha se adaptado à adoção de energias renováveis, a participação pretérita do Estado na promoção daquelas fontes de energia renovável terá sido fundamental.

\section{Uma agenda macroeconômica (quase) completa para a sustentabilidade}

Mas quem resume melhor e de forma mais completa a visão de um "keynesiano ambiental", na nossa perspectiva, é Nadal (2011). Sua "macroeconomics for sustainability", ancorada na perspectiva pós-keynesiana, é uma agenda que consiste de algumas propostas que coincidem com as de Mazzucato (2013), como: (i) subsidiar as atividades econômicas 'verdes', especialmente as mais inovadoras, (ii) usar de forma apropriada e heterogêneas as políticas fiscal, monetária e creditícia, e (iii) utilizar políticas a nível setorial, como as industriais e de inovação, se possível a nível regional. A estas propostas somam-se a necessidade de combater as desigualdades, de administrar as taxas de câmbio e de regular as finanças. 
Até pouco tempo, o pós-keynesianismo nem sempre teve uma relação muito saudável com o desenvolvimento sustentável, dado o seu foco quase que exclusivo no desenvolvimento a qualquer custo, com distribuição de renda ${ }^{21}$. Trabalhos recentes, no entanto, como os capítulos do livro organizado por Holt, Pressman e Spash (2010), ajudaram a alterar um pouco esse quadro. O argumento central é que se as atividades 'verdes' certas forem estimuladas, a preocupação com o'estrago' provocado pelo crescimento pode ser significativamente minimizada. A energia e os materiais, bem como os alimentos, passariam a ser produzidos sob uma lógica não destrutiva. Com maciços estímulos à "biomass-based industry" (Bomtempo, 2012), por exemplo, seria possível produzir energia e materiais com qualidade equivalente àquelas dos derivados do petróleo. Neste diapasão, a discussão em torno da perspectiva do "degrowth ${ }^{22 "}$ tornar-se-ia secundária, por que crescer seria muito menos danoso. Com os atuais padrões de distribuição de renda, difíceis de serem alterados, crescer ainda parece ser importante para que diminuam as desigualdades.

\section{Estado, deliberação e patentes}

Mas que Estado queremos? Isto é que, instituições queremos? No seu '21st century developmental state' Peter Evans (Evans, 2008) enfatizou corretamente que " (...) deliberative institutions and the broad based connections between state and civil society that they entail are the only way to ensure (...) the flows of information necessary to guide the allocation of public resources (...)" (Evans, 2008, p. 18). Assim, a participação da população nos processos deliberativos é fundamental para a desejável co-formatação das políticas públicas.

Nesta veia, para que a agenda pós-keynesiana para a sustentabilidade de Nadal (2011) seja bem sucedida, é fundamental a existência de um Estado que encoraje, em seus canais de deliberação, a agência individual ou coletiva, seja através dos canais políticos tradicionais, seja através da sociedade civil. É neste sentido que destacamos a importância do que Enrique Leff (2006) chama de "process of environmentalisation of struggles", que permite a todo tempo criar novas junções críticas em que os atores sociais possam deliberar e demandar novas estratégias e respostas ao Estado.

Em primeiro lugar, para assegurar que o conhecimento flua da forma mais livre possível, vivemos como argumenta, Pasinetti (2009), em um mundo em que o conhecimento é artificialmente protegido por patentes. No entanto, com o reconhecimento da importância dos "sistemas de inovação", ficou para trás o argumento de que a escala - isto é, as tecnoestruturas, na linguagem de Galbraith (1988) - importa na difusão tecnológica. Com a flexibilização das patentes, os 'sistemas de inovações' compartilhariam de forma mais eficiente o conhecimento, de maneira que o ritmo do aparecimento das inovações capazes de produzir energia renovável sustentável fosse acelerado, através de um processo de 'circular cumulative causation $^{23}$. Outro ponto importante é que as patentes tendem a encarecer o custo da instalação de equipamentos que produzem energia renovável. Por outro lado, na 
"biomass-based industry" (Bomtempo, 2012) a proteção das patentes ainda é um tema delicado ${ }^{24}$. Em resumo, é necessário, então, um marco institucional que permita a difusão mais livre possível das informações necessárias para que o ritmo de inovações possa se acelerar, mas que ao mesmo tempo remunere, de alguma maneira, firmas inovadoras em alguns campos. São instituições capazes de compreender que existe um delicado equilíbrio entre (i) as patentes como fonte de viabilidade econômica das inovações e (ii) a remoção das patentes como condição importante para que essas soluções inovadoras sejam adotadas em larga escala.

Em segundo lugar, a co-formatação das políticas públicas tem se revelado fundamental para que se repense os atuais padrões de consumo e nosso modo de produção: do transporte individual para o transporte coletivo, do consumo conspícuo para o consumo consciente, de jornadas de trabalho extenuantes e realizadas distantes das moradias para o homeworking, para que a riqueza exagerada nas mãos de poucas seja redistribuída, e assim por diante. As mudanças, neste contexto, em grande parte viriam de baixo para cima. Em grande parte, estas são fundamentais por que existem certas matérias primas que nem uma "biomass-based industry" que certamente fará parte da solução - conseguirá fornecer, sobretudo os metais. Além disso, o agronegócio - no qual está inserido a "biomass-based industry" - como mostra relatório do (PNUD-ONU), consome cerca de 70\% da água do planeta, em nível mundial. Neste diapasão, conforme Resnick e Wolff (2006), é impossível identificar e antecipar todas as externalidades negativas de um ato econômico, de um evento ou de uma instituição, já que cada um desses possuem uma infinidade de efeitos no presente e outros que se estendem para o infinito. O'Hara (2009), argumentaria, de forma análoga, que as externalidades negativas ${ }^{25}$ devem ser lidas como contradições insolúveis que são inerentes ao sistema capitalista. Assim, a ação de um Estado todo poderoso e benevolente nunca será capaz de neutralizar todas as externalidades negativas decorrentes da "economia verde" ou remover por completo as contradições do modelo econômico em gestação. Ganha força, assim, a posição da ecologia política de que o crescimento econômico não é um fim em si mesmo, de que as gerações atuais devem assumir a sua responsabilidade com relação às gerações futuras, e de que se deve respeitar a integridade dos sistemas naturais que tornam possível a vida no planeta (Svampa, 2013) ${ }^{26}$.

Do ponto de vista da teoria da qual nos servimos neste artigo, um Estado no qual a agência individual ou coletiva seja permitida ou eventualmente encorajada para que os fins acima mencionados sejam atingidos, as mudanças serão induzidas tanto pelos "rule makers" como pelos "rule takers". De maneira a acelerar os processos de mudança, estes últimos exerceriam a função de um "countervailing power"27" em relação aos interesses privados - que continuarão advogando pela continuidade da produção de energia fóssil, com o argumento de que sua cadeia de valor é importante para a economia, que gera empregos, e que o provimento de energia fóssil é fundamental para reduzir o fosso entre ricos e pobres ${ }^{28}$. 


\section{Conclusões}

O objetivo deste artigo foi analisar, em um contexto aparentemente favorável para a difusão das energias renováveis no mundo - que parte, entretanto, de uma base bastante fóssil -, se o principal lócus das mudanças será a dimensão mundial (governança global) ou se os Estados nacionais (governança estatal) carregarão esta responsabilidade? Em outras palavras, o vetor de mudanças é exógeno ou endógeno às economias políticas nacionais? Para responder a essas perguntas, recorremos à perspectiva teórica das "instituições como regimes", tal como esta é apresentada por Streeck e Thelen (2009).

Analisamos primeiro a possibilidade de que a dimensão mundial - isto é, a governança global - fosse esse lócus. Vimos que a forma como o petróleo é precificado no mundo não favorece as mudanças, por que existe uma possibilidade de que os preços aumentem novamente, viabilizando os chamados petróleos não-convencionais. A introdução de um imposto sobre o carbono quando os preços estão baixos, como sugere Sachs (2014), pode, assim, não ser bem sucedida. Vimos também que os instrumentos acordados a nível global - ao longo das COPs-, para, entre outras tarefas, mudar o perfil da matriz energética global, não tiveram muito sucesso, por colocarem um peso excessivo nos instrumentos de mercado. Ademais, essas conferências até agora não obtiveram muito sucesso em confrontar os interesses econômicos das principais potências econômicas do mundo. Assim, a nível global, argumentamos que os "rule takers" da perspectiva de Streeck e Thelen (2009) conseguem reescrever as regras a seu favor ou são eles mesmos os "rule makers".

Depois disso, analisamos a possibilidade de que os Estados nacionais - onde predomina a governança estatal - fosse o centro dinâmico que deflagrasse as mudanças. Vimos que os Estados nacionais sempre foram muito eficazes em estabelecer impostos, o que pode ser um ponto favorável ao estabelecimento de um imposto sobre o carbono a nível nacional. Além disso, com base em Mazzucatto (2013), Drechsler (2011) e Nadal (2011), vimos que o Estado tradicionalmente tem sido o principal incentivador de novas rotas tecnológicas: sem os seus incentivos, seja na forma de subsídios, políticas fiscais direcionadas, ou como produtor, dificilmente as tecnologias que tornam possível a produção de energia renovável em larga escala teria se massificado. Neste sentido, argumentamos que ao nível da governança estatal, o Estado pode funcionar como um "rule maker" eficaz.

No entanto, vimos que a deliberação, isto é, a possibilidade de que a sociedade civil ou as forças políticas tradicionais participem da co-formatação das políticas públicas, pode ser importante para acelerar o ritmo da difusão de fontes de energia renovável. Em primeiro lugar, por que as patentes podem encarecer excessivamente algumas fontes de energia renovável. Em segundo lugar, por que esses canais de coformatação de políticas públicas são importantes para que se alterem os padrões de consumo e de produção, uma vez que há limites - sobretudo políticos e materiais - à 
possibilidade do Estado ser o agente transformador benevolente. Neste contexto, a transformação viria também de baixo para cima, onde os "rule takers" contestariam a todo tempo as decisões tomadas pelos "rule makers".

Neste ponto, já temos suficientes elementos para responder, de forma tentativa, o que motivou a assinatura de um acordo de cooperação entre os Estados Unidos e a China, onde estes se comprometem a reduzir as suas emissões, antecipando-se à COP 21, a ser realizada neste ano em Paris. Do nosso ponto de vista, foram os interesses econômicos, políticos e geopolíticos de cada nação - portanto endógenos - que levaram à assinatura do acordo. Existe, por exemplo, a percepção de que a energia renovável é um nicho de negócios rentável capaz de gerar "empregos verdes", em um contexto de crise econômica mundial. Ademais, as patentes que podem ser obtidas neste campo poderão se revelar, no futuro, um importante vetor de crescimento econômico, sobretudo no campo da bioenergia. Na China, há o interesse de reduzir as emissões de $\mathrm{CO}_{2}$ devido à queima do carvão para fins de geração elétrica, que tem impactado a saúde das populações locais. Nos Estados Unidos, há atualmente em curso uma tentativa de reduzir a dependência externa de energia, para a qual as energias renováveis podem ser um instrumento importante. Esse esforço de diversificação também tem sido empreendido pela China. Nos Estados Unidos, a opinião pública tem se mostrado favorável à difusão das energias renováveis, ainda que parcelas grandes da população se mostrem céticas em relação ao aquecimento global. Por fim, para a China, ser um líder na produção de energia renovável auxiliaria no seu projeto de se projetar cada vez mais geopoliticamente no mundo ${ }^{29}$.

Contudo, interpreta-se que as iniciativas chinesa e estadunidense - de cunho claramente endógeno - podem funcionar como 'externalidades de rede' para os regimes internacionais que governam o petróleo e o clima. Se esses países forem bem sucedidos na difusão e no barateamento de fontes de energia renovável, estas podem ser exportadas, com maior facilidade, para outros países. Em suma, se a tecnologia é desenvolvida nos grandes centros, a periferia pode atingir as suas metas com maior facilidade. Com a ajuda do recém-criado banco dos BRICS, talvez seja possível suprir eventuais escassezes de investimento a nível local. Prevaleceria, no entanto, a ideia de uma barreira ou uma "ilusão do desenvolvimento", conforme Arrighi (1990), já que a vantagem econômica de produzir energia renovável se concentraria no centro, e não na periferia. Em resumo, muito embora os investimentos estatais de alguns grandes players como China, Alemanha e Estados Unidos gerem 'externalidades de redes' que possivelmente viabilizem futuros acordos climáticos, o crescimento da energia renovável no mundo fosse "state-led", e não "regime-led", tomando emprestada uma expressão típica dos modelos de desenvolvimento econômico.

Entretanto, um mundo multipolar conectado em uma grande rede está longe de prover eficiência irrestrita na difusão de energias renováveis, no sentido dos acima aludidos Resnick e Wolff (2006). É altamente improvável, por exemplo, que um país como o Brasil deixe de recorrer ao gás natural para fins de geração térmica quando seu 


\begin{abstract}
abastecimento de energia hidráulica for deficitário ou quando os planos de expandir a produção de biocombustíveis de segunda geração não forem bem sucedidos, a despeito dos acordos internacionais que forem assinados no futuro. Além disso, é muito difícil prever o momento exato em que o país perceberá que a sua cota de petróleo produzido vis-à-vis seu projeto desenvolvimentista terá sido suficiente, já que o regime internacional que rege a precificação dessa commodity facilmente produz uma "adição fóssil". Os interesses locais tendem a predominar, de maneira que ainda estamos muito longe daquele momento da história onde a era do petróleo se exaure não pela falta de pedras, mas pela descoberta de novas tecnologias.
\end{abstract}

\begin{abstract}
Notas
1 De fato, como mostra Schutte (2014), o 4 relatório do IPCC já tinha marcado uma inflexão importante, pelo impacto causado com a afirmação de que é "muito provável" que a ação humana seja a causa do aquecimento global. Neste diapasão, o $5^{\circ}$ relatório, ao qual aludimos nesta introdução, tornou as evidências ainda mais robustas.

2 Em um importante artigo, O'Hara (2009) analisa como as mazelas ambientais têm efeitos cumulativos (multiplicadores) umas sobre as outras.

3 Sobre o limitado efeito de algumas dessas conferências ver Serôa da Motta (2010, 2011), Altvater e Brunnengräber (2011) e Bond (2012)

${ }^{4}$ Disponívelem:http://www.project-syndicate.org/commentary/fossil-fuels-carbon-pricing-tax-by-jeffreyd-sachs-2014-12

${ }^{5}$ O momento é favorável também por que, como argumenta Biel $(2013,67)$, "the weird thing is that 'green capitalism' can actually be highly succesful at the level of particular businesses or even (as in the industrial ecology model) districts" E, ademais, já se observam mudanças substanciais se descermos um ou mais níveis: do capitalismo global para as realidades locais. Como mostra Gudynas (2013), a transição implica mudanças em várias escalas, desde a local, onde aparentemente as mudanças pareçam insignificantes. Essa transição pode-se dar também, por exemplo, nos moldes do 'buen vívir', que já encontra algum grau de adesão em países andinos, ou de acordo com os parâmetros da 'economia solidária'.

${ }^{6}$ Tanto a produção estimada quanto os valores investidos superam o que a Petrobras, suas parceiras e as concorrentes conseguirão efetivamente produzir e investir.

7 Removendo os subsídios ao biodiesel.

8 http://www.powermag.com/u-s-can-reach-50-renewable-generation-by-2030-says-irena/

9 Para mais informações http://www.thesolarfoundation.org/

${ }^{10}$ Para a autora, a governança estatal diz respeito"à capacidade governativa em sentido amplo, envolvendo a capacidade de ação estatal na implementação das políticas e na consecução das metas coletivas (DINIZ, 1998b, p. 278)." Neste sentido, governance (ou governança) diz respeito a quatro dimensões essenciais (DINIZ, 1995, p. 401): (I) a capacidade de comando e de direção do Estado, tanto internamente, em face do conjunto da máquina estatal e da sociedade, como externamente vis-à-vis a inserção do país no sistema internacional; (II) a capacidade de coordenação do Estado entre as distintas políticas e os diferentes interesses em jogo; (III) a capacidade de implementação; (IV) a capacidade de interlocução com os atores envolvidos" (DINIZ, 1998b, p. 279).

${ }^{11}$ Lei no 12.187, de 29 de dezembro de 2009.

${ }^{12}$ Dentre os instrumentos econômicos elencados constam mecanismos creditícios e mecanismos de mercados de carbono.

${ }^{13}$ Essa ênfase no desmatamento como fonte de reduções das emissões se deve a, no mínimo, seis fatores: (i) O desmatamento é responsável atualmente por cerca de $60 \%$ do total das emissões, conforme tabela abaixo, o que torna necessário focar as atenções neste problema; (ii) a comunidade internacional tradicionalmente pressiona o Brasil em relação a esse tema; (iii) a implantação de MDLs na Amazônia tem o potencial de gerar renda para os habitantes locais; (iv) A atividade energética tem um custo de oportunidade muito superior, de tal maneira que reduzir emissões na Amazônia resulta mais barato para o país como um todo; (v) preocupações com a segurança energética do país; (vi) a existência de um profícuo mercado internacional que demanda projetos de $\mathrm{MDL}$, principalmente em países como o Brasil.
\end{abstract}


${ }^{14}$ Os números de Serôa da Motta (2011) são ligeiramente diferentes daqueles apresentados pela $2^{a}$ Comunicação Nacional do Brasil à COP. Como Serôa da Motta (2011) apresenta a comparação com 2020, optou-se por usar as duas versões.

${ }^{15}$ Entre 3-5\% durante a etapa da produção. Durante os Testes de Longa Duração este percentual é maior, uma vez que as instalações necessárias para evitar a queima de gás natural, como os gasodutos, ainda não foram completamente instalados. A simples liberação de gás natural é muito mais danosa do que a queima do gás natural, onde se permite uma maior queima nessa fase inicial.

${ }^{16}$ Além do $\mathrm{CH} 4$ (metano) e do CO2 (dióxido de carbono), são considerados gases do efeito estufa: o N2O (óxido de nitrose), os HFC (hidrofluorcarbonos) e os PFC (perfluorcarbonos).

${ }^{17}$ Alguns exemplos: "Convenção Internacional sobre Responsabilidade Civil por Danos Causados por Poluição por Óleo - CLC/69"; Convenção Internacional para a Prevenção da Poluição por Navios MARPOL; CNDUM (Convenção das Nações Unidas sobre os Direitos do Mar); "International Convention on Oil Pollution Preparedness, Response and Co-operation"; e International Convention for the Control and Management of Ships'Ballast Water and Sediments

${ }^{18}$ Para uma análise bastante completa sobre o "urban sprawl", veja Gonzalez (2006) e Urry (2013).

${ }^{19}$ A ideia de que a indústria "vende" um futuro fóssil e de que sugere que somente a inovação tecnológica - desde que economicamente viável - pode levar a mudanças substanciais rumo a uma matriz energética baseada em energias renováveis, encontra grande respaldo teórico em Courvisanos que, inspirado em Michal Kalecki, formula a tese dos "aspectos políticos da inovação" (Courvisanos, 2009). Nesta abordagem, as grandes corporações, muitas vezes com o apoio do Estado, buscam proteger os atuais modelos de produção e militam para que a adoção de novas tecnologias seja postergada. De forma a proteger seus interesses, agem politicamente para prolongar o ciclo de vida de um dado paradigma 'técnico-econômico' - como, por exemplo, aquele baseado em energia fóssil - dessa forma adiando a quebra de paradigma - por exemplo, em direção a uma maior difusão de energias renováveis.

${ }^{20}$ Não tendo logrado promover-se industrialmente, a estratégia saudita é de buscar a valorização do preço do petróleo a longo prazo. Para tal, conta com reservas internacionais que lhe permitem tolerar alguns anos de baixos preços. Mas, no longo prazo, por espantoso que isso possa parecer, o país padece de uma espécie de 'maldição dos recursos naturais', como explicam El Gamal e Jaffe (2010)

21 Veja, por exemplo Chester e Paton (2012).

22 Para uma análise detalhada dessa tese e de suas implicações,veja Victor (2008).

23 "Circular cumulative causation' é um conceito original concebido pelo economista sueco Gunnar Myrdal, em 1957. Trata-se de ideia de que os efeitos de uma ação (ou instituição) podem levar a outras ações ou mudanças em outras instituições, de forma cumulativa. O conceito deu origem aos modelos de crescimento kaldorianos. A esse respeito, ver O'Hara (2000) e Pasinetti (2009)

${ }^{24}$ Sobretudo do ponto de vista das empresas brasileiras, que possuem poucas patentes registradas neste campo.

${ }^{25}$ Externalidades negativas, por definição podem ser anuladas por alguma ação compensatória.

${ }^{26}$ Luta-se - em linha com Martínez-Alier, que argumenta que na economia ecológica "distribuição" não significa somente distribuição econômica, pois igualmente diz respeito à distribuição ecológica (Martínez-Alier, 2007, p. 49) - para que a discussão sobre a distribuição dos benefícios da atividade econômica esteja alinhada à discussão sobre a distribuição dos danos ecológicos. Luta-se - em linha com Magdoffe Foster (2011), que argumentam que os problemas ambientais não poderão ser resolvidos somente através de tecnologias mais eficientes ou através dos mercados - para que se transformem as relações "in community, culture, and economy, in how we relate to each other as human beings, and how we relate to the planet (Magdoff e Foster, 2011, p. 122)".

${ }^{27} \mathrm{O}$ conceito de 'countervailing power', criado por J.K. Galbraith, remete à noção de que uma instituição, uma organização ou um ator social pode usar sua agência para se apor às decisões de outrem. Ver Galbraith (2009)

${ }^{28}$ Para um apanhado desses argumentos, ver a "Agenda Prioritária da Indústria de Petróleo, Gás e Biocombustíveis - 2014-2015" do IBP, disponível em http://issuu.com/ibp_pub/docs/ibp_agendaprioritaria_ web? mode=embed\&layout =http $\% 3 \mathrm{~A} \% 2 \mathrm{~F} \% 2 \mathrm{Fskin}$.issuu.com $\% 2$ Fv\%2Flight $\% 2$ Flayout. xml\&backgroundColor=e6e6e6

${ }^{29}$ Algo que já faz, por exemplo, no âmbito da promoção do seu Yuan Renmibi em certas relações bilaterais, enquanto alternativa ao dólar. 


\section{Referências bibliográficas}

ALTVATER, E.; BRUNNENGRÄBER, A. After Cancún. Wiesbaden: Springer, 2011.

ARRIGHI, G. The Developmentalist Illusion: A Reconceptualization of the Semiperiphery. In.: MARTIN, W.G. Semiperipheral States in the World-Economy. Westport: Greenwood Press, 1990. pp. 11-42.

BIEL, R. The entropy of capitalism. Chicago: Haymarket Books, 2013.

BOMTEMPO, J.V. O futuro dos biocombustíveis. In.: DUAILIBE, A.K. Combustíveis no Brasil. Rio de Janeiro: Synergia, 2012. pp.114-127

BOND, P. Politics of Climate Justice. Scotsville: University of KwaZulu-Natal Press, 2012

BRASIL. Lei no 12.187, de 29 de dezembro de 2009. Institui a Política Nacional sobre

Mudança do Clima - PNMC e dá outras providências.. Lex: Diário Oficial [da

República Federativa do Brasil], Brasília, 2009. Disponível em <

http://www.planalto.gov.br/ccivil_03/_ato2007-2010/2009/lei/l12187.htm>. Acesso em 18 mar. 2015.

BRIDGE, G.; LE BILLON, P. Oil. Cambridge: Polity, 2013.

BRUNNENGRÄBER, A. Die Ökonomie des Klimawandels. Ökologisches Wirtschaften, n. 4, 2008.

CAMARGO, A. New Deal verde e desenvolvimento sustentável: um novo ciclo virtuoso para o desenvolvimento? In.: VELLOSO, J.P.R.; ALBUQUERQUE, R.C. A questão ambiental e a Rio + 20. Rio de Janeiro: Campus, 2012. pp.13-46

CAROLLO, S. Understanding Oil Prices. Chichester: Wiley Finance, 2012.

CHESTER, L.; PATON, J. Greening economic theory: Heterodox possibilities. Paper presented at the 2012 Association of Heterodox Conference, 2012.

COLL, S. Private Empire: ExxonMobil and American Power. New York: Penguin, 2012.

COURVISANOS, J. Political Aspects of Innovation, Research Policy, 38 (7), 1117-24, 2009.

DI MUZIO, T. The crisis of petro-market civilization: the past as prologue? In.: GILL, S. (ed.) Global Crises and the Crisis of Global Leadership. New York: Cambridge University Press, 2012. pp.73-88

DINIZ, E. Governabilidade, Democracia e Reforma do Estado: Os Desafios da Construção de uma Nova Ordem no Brasil dos anos 90. Dados - Revista de Ciências Sociais, Rio de Janeiro, Vol. 38. No 3. 1995. pp. 385-415.

- Governabilidade, governance e reforma do Estado: considerações sobre o novo paradigma. Revista do Serviço Público/Fundação Escola Nacional de Administração Pública, vol. 1, no 1, mai-ago/1996.

. Uma perspectiva analítica para a reforma do Estado. Lua Nova, no. 43, São Paulo, 1998a.

. Governabilidade e democracia. In.: RUA, M.G.; CARVALHO, M.I.V. (orgs.) O estudo da política. Brasília: Paralelo 15, 1998b. pp.261-290

. O Pós-Consenso de Washington: globalização, Estado e governabilidade reexaminados. In: DINIZ, E. (org) Globalização, Estado e Desenvolvimento. Rio de Janeiro: FGV, 2007.

DRECHSLER, W. Governance In and Of Techno-Economic Paradigm Shifts: Considerations For and From the Nanotechnology Surge. In.: DRECHSLER, W.; KATTEL, R.; REINERT, E.S. (eds.) Techno-Economic Paradigms: Essasys in Honour of Carlota Perez. London: Tulika, 2011. pp. 95-104.

DUGGER, W.M., SHERMAN, H.J. Reclaiming Evolution. London: Routledge, 2000. 
EAGLETON, T. Ideologia: uma introdução. São Paulo: Boitempo Editorial, 1997.

EL-GAMAL, M. JAFFE, A.M. Oil, Dollars, Debt, and Crises: The Global Curse of Black Gold. Cambridge: Cambridge University Press, 2010.

EVANS, P. In Search of the 21st Century Developmental State. The Centre for Global Political Economy. University of Sussex. UK. Working Paper № 4, 2008.

EXXONMOBIL. Outlook for Energy - a view for 2040. 2015. Disponível em: http://cdn.exxonmobil. com/ /media/Reports/Outlook\%20For\%20Energy/2015/2015-Outlook-for-Energy_print-resolution.pdf

FIORI, J.L. História, Estratégia e Desenvolvimento. São Paulo: Boitempo Editorial, 2014.

GALBRAITH, J.K. O novo estado industrial. São Paulo: Nova Cultural, 1988. . Capitalismo Americano. São Paulo: Novo Século, 2009.

GILL, S. Leaders and led in an era of global crises. In. GILL, S. Global Crises and the Crisis of Global Leadership. Cambridge: Cambridge University Press, 2012. pp. 23-37

GONZALEZ, G. An Eco-Marxist Analysis of Oil Depletion via Urban Sprawl. Environmental Politics, vol. 15, no. 4, 515 - 531, agosto de 2006.

GUDYNAS, E. Transitions to post-extractivism: directions, options, areas of action. In.: LANG, M., MOKRANI, D. Beyond Development: Alternative Visions from Latin America. Quito: Fundación Rosa Luxemburgo, 2013. pp. 165-188

GUSTAFSON, B. Fossil Knowledge Networks: Industry Strategy, Public Culture and the Challenge for Critical Research. In.: MCNEISH, J.-A.; LOGAN, O. (orgs.) Flammable Societies. London: Pluto Press, 2012. pp.311-334

HARVEY, D. The Enigma of Capital. New York: Oxford, 2010.

HOLT,R.P.F.; PRESSMAN, S.; SPASH, C. Post Keynesian and Ecological Economics: Confronting Environmental Issues. Cheltenham: Edward Elgar, 2009.

IBP. Agenda Prioritária da Indústria de Petróleo, Gás e Biocombustíveis - 2014-2015. Disponível em http://issuu.com/ibp_pub/docs/ibp_agendaprioritaria_web?mode=embed\&layout=http\%3A\%2F\%2Fskin.issuu.com\%2Fv\%2Flight\%2Flayout.xml\&backgroundColor=e6e6e6.

IEA. World Energy Outlook. Paris: OECD/IEA, 2013.

IRENA. U.S. Can Reach 50\% Renewable Generation by 2030, Says IRENA. PowerMag, 01/12/2015. Disponível em http://www.powermag.com/u-s-can-reach-50-renewable-generation-by2030-says-irena/

JACOBS, M. The Real Lima Deal. Project Syndicate, 15/12/2014. Disponível em: < https://www. project-syndicate.org/commentary/lima-global-climate-change-agreement-by-michael-jacobs-2014-12>

JIANKUN, H.; STERN, N. China's Climate Commitment. Project Syndicate, 23/07/2014. Disponível em: <http://www.project-syndicate.org/commentary/he-jiankun-and-nicholas-stern-praise-thechinese-authorities-for-their-efforts-to-fight-global-warming>

LEFF, E. La Ecología Política en América Latina. Un campo en construcción. In: ALIMONDA, $\mathrm{H}$.(ed.): Los tormentos de la materia. Aportes para una ecologia política latinoamericana. Buenos Aires: CLACSO, 2006, pp. 21-39.

LISTER, M.; MARSH, D. Conclusion. In.: HAY, C., LISTER, M., MARSH, D. (eds.) The State: Theories and Issues. Basingstoke: Palgrave MacMillan, 2005. p. 248-260.

MAGDOFF, F.; FOSTER, J.B. What Every Environmentalist Needs to Know About Capitalism. Nova lorque: Monthly Review Press, 2011. 
MARTÍNEZ-ALIER, J. O Ecologismo dos Pobres. São Paulo: Editora Contexto, 2007.

MAZZUCATO, M. The entrepreneurial state. London: Anthem Press, 2013.

MITCHELL, T. Carbon Democracy. New York: Verso, 2011.

MCNEISH, J-A.; LOGAN, O. Conclusion: All Other Things Do Not Remain Equal. In.: MCNEISH, J.-A.; LOGAN, O. (orgs.) Flammable Societies. London: Pluto Press, 2012. pp.335-352

MUSGRAVE, R. Theories of Fiscal Crisis: an Essay in Fiscal Sociology. In.: BOSKIN, M. (ed.). The Economics of Taxation. Washington DC: Brookings, 1980-81.

NADAL, A. Macroeconomics for sustainability. London: Zed Books, 2011.

NAYYAR, D. A corrida pelo crescimento: países em desenvolvimento na economia mundial. Rio de Janeiro: Contraponto, 2013.

NEWELL, P., PATERSON. M. Climate Capitalism. Cambridge: Cambridge University Press: 2010.

NOBRE, M., AMAZONAS,M.C (org). Desenvolvimento Sustentável. Brasilia:.Edições Ibama, 2002.

OFFE, C. Strukturprobleme des kapitalistischen Staates: Aufsätze zur Politischen Soziologie. Frankfurt: Campus Verlag, 2006.

O'HARA, P.A. Marx, Veblen, and Contemporary Institutional Political Economy. Cheltenham: Edward Elgar, 2000.

- Political economy of climate change, ecological destruction and uneven development. Ecological Economics, n 69, 2009. pp.223-234.

PASINETTI, L. Keynes and the Cambridge Keynesians. Cambridge: Cambridge University Press, 2009.

PEREZ, C. Technological Revolutions and Financial Capital: The Dynamics of Bubbles and Golden Ages. Cheltenham: Edward Elgar, 2003.

PINTO JR., H. Q. (org.). Economia da Energia. Rio de Janeiro: Campus, 2007.

RESNICK, S.A.; WOLFF, R. New Departures in Marxian Theory. London: Routledge, 2006.

RODRIK, D. From Welfare State to Innovation State. Project Syndicate, 14/01/2015. Disponível em: <http://www.project-syndicate.org/commentary/labor-saving-technology-by-dani-rodrik-2015-01>

SACHS, J.D. Financing Climate Safety. Project Syndicate, 26/12/2014. Disponível em: <https:// www.project-syndicate.org/commentary/fossil-fuels-carbon-pricing-tax-by-jeffrey-d-sachs-2014-12>

SERÔA DA MOTTA, R. A Regulação das emissões de gases de efeito estufa no Brasil. In. SALGADO, L.H.; FIUZA, E. (org). Marcos Regulatórios no Brasil: revendo o papel do Estado após a crise financeira. Rio de Janeiro: Ipea, 2010. p. 307-325 - A Política nacional sobre mudança do clima: aspectos regulatórios e de governança. In. SERÔA DA MOTTA, R. (org). Mudança do clima no Brasil: aspectos econômicos, sociais e regulatórios. Brasilia: Ipea, 2011. p. 31-42

SERRANO, F. A Economia Americana, o Padrão Dólar Flexível e a Expansão Mundial nos Anos 2000. In. FIORI, J.L.; MEDEIROS, C.; SERRANO, F. O Mito do Colapso do Poder Americano. Rio de Janeiro: Record, 2008. p.71-172

SHAH, S. Crude: the story of oil. New York: Seven Stories Press, 2004.

SCHUTTE, G.R. Energia e Desenvolvimento Sustentável no Brasil - Trajetórias recentes e perspectivas. Análise, Friedrich Ebert Stiftung Brasil, agosto de 2014. 
SHORT, N. Leadership, neoliberal governance and global economic crisis: a Gramscian Analysis. In. GILL, S. Global Crises and the Crisis of Global Leadership. Cambridge: Cambridge University Press, 2012. pp.38-55

SILVA, C.M.S. Reforma tributária: a CIDE e a variação de preços de combustíveis no Brasil. In.: BICALHO, R. (org). Ensaios sobre política energética. Rio de Janeiro: Interciências, 2007. pp.116-9

STILWELL, F. Political Economy: The Contest of Economic Ideas. Melbourne: OUP Australia and New Zealand, 2012.

STREECK, W.; THELEN, K. Institutional Change in Advanced Political Economies. In. HANCKÉ, B. (org). Debating Varieties of Capitalism. New York: Oxford University Press 2009. p. 95-131

SVAMPA, M. Resource extractivism and alternatives: Latin American perspectives on development.In.: LANG, M., MOKRANI, D. Beyond Development: Alternative Visions from Latin America. Quito: Fundación Rosa Luxemburgo, 2013. pp. 117-144

URRY, J. Societies beyond oil. Zed Books: London, 2013.

VAN DER PLOEG, F. Macroeconomics of sustainability transitions: Second-best climate policy, Green Paradox, and renewables subsidies. Environmental Innovation and Societal Transitions, v.1, p. 130-134, 2011.

VICTOR, P. Managing Without Growth. Cheltenham: Edward Elgar, 2008

WEISS, L. The myth of the powerless state. Ithaca: Cornell University Press, 1998

WINNETT, A. Environmental Economics. In.: KING, J.E. (ed.) The Elgar Companion to Post Keynesian Economics. Chelthenham: Edward Elgar, 2012. pp.170-175

YERGIN, D. The Prize. New York: Free Press, 2003.

ZALIK, A. Oil 'futures': Shell's Scenarios and the social constitution of the global oil market. Geoforum, n. 41, 2010, p. 553-564,

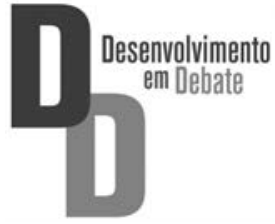

